\title{
Physical modeling of local scour development around a large-diameter monopile in combined waves and current
}

\author{
Wen-Gang Qi, Fu-Ping Gao* \\ Key Laboratory for Mechanics in Fluid Solid Coupling Systems, Institute of Mechanics, Chinese Academy of Sciences, Beijing 100190, China
}

\section{A R T I C L E I N F O}

\section{Article history:}

Received 18 February 2013

Received in revised form 28 July 2013

Accepted 3 October 2013

Available online 29 October 2013

\section{Keywords:}

Monopile

Local scour

Pore pressure

Combined waves and current

\begin{abstract}
A B S T R A C T
In most of the previous studies on local scour around pile foundations, wave-induced pore pressure response has not been taken into account. The local-scour and pore-pressure responses around a large-diameter monopile in combined waves and current have been physically modeled with a specially-designed flow-structure-soil interaction flume. In the series of experiments, the time developments of the scour-depth and the porepressure in the proximity of the model pile were measured simultaneously. Experimental results indicate that the wave-induced upward seepage under the wave troughs may weaken the buoyant unit weight of the surrounding sand, which brings the sand-bed more susceptible to scouring. The superimposition of the waves on a current has much effect on the time-development of local scour and the resulting equilibrium scourdepth, which is particularly obvious when the sand-bed is in the clear-water regime under the current or waves alone respectively. It is observed that the maximum flow velocity at the boundary layer for the following-current case is larger than that for the opposing-current case, which further results in faster time development of scour depth and greater equilibrium scour depth for the following-current case.
\end{abstract}

(c) 2013 Elsevier B.V. All rights reserved.

\section{Introduction}

In the coastal and offshore engineering, piled foundations have been widely used for supporting various structures, e.g. fixed-type platforms, cross-bay bridges, and near-shore wind turbines. In the recent decades, quite a few monopiles with large diameters up to $6 \mathrm{~m}$ were constructed in the near-shore wind farms. Due to the large slenderness ratios (i.e. the ratio of pile diameter to pile embedded length) typically employed for the existing monopile foundations, the scour depth could be up to $25 \%$ of the embedded pile length (Sørensen et al., 2011).

In the severe shallow water environments, ocean waves and current are usually coexisting, which may bring the soil responses around marine structures more complicated than that due to wave or current alone. The sediment movement at the soil surface in the local scour process is often accompanied with cyclic pore pressures generated in the soil around the monopile. A better understanding of the fluidpile-soil coupling mechanism would be crucial for proper prediction of the maximum scour depth of a large-diameter monopile in combined waves and current.

\subsection{Scour at pile foundation in current-alone}

Local sediment scour at circular piles has been studied by many researchers over the last 4 decades. In the river hydraulics, the local scour at the bridge piers has proven to be one of main causes for the

\footnotetext{
* Corresponding author. Tel.: +8610 82544189; fax: +861062561284.

E-mail address: fpgao@imech.ac.cn (F.-P. Gao).
}

structure failure (Melville and Coleman, 2000). The phenomenon of scouring at bridge piers has been studied extensively from various aspects, including flow characteristics \& local scour mechanism and prediction of maximum scour depth. Comprehensive descriptions of scour around the pile or bridge pier in a steady current have been given by Hoffmans and Verheij (1997), Whitehouse (1998), and Sumer and Fredsøe (2002).

The dominant feature of the flow near a pile is the large-scale eddy structure, or the system of vortices including the horseshoe vortex, the wake vortex, and/or the trailing-vortex system. If the scouring potential created by those vortices is strong enough to overcome the particles' resistance to motion, local scour will be initiated around the pier. The existing test observations indicated that the horseshoe vortex (including the down-flow) has a dominant effect on the local scour in currents alone. With the development of the scour hole, the vortex rapidly grows in size and strength as additional fluid attains a downwards component and the strength of the down flow increases (see Breusers et al., 1977). Based on the flow measurements by the ADV within the intermediate and equilibrium scour holes, the characteristics of horseshoe vortex at circular and square piers have been further investigated (Dey and Raikar, 2007).

The equilibrium scour depth prediction is a key concern in the geotechnical design for the coastal and offshore foundations. Experimental results of Raudkivi and Ettema (1983) indicate that the equilibrium scour depth under clear-water condition is related to the particle size distribution and the mean particle size of bed sediment, flow depth relative to both the pier diameter and the particle size of the sediments, etc. The equilibrium scour depth was ever taken as 
lower values (e.g., $S / D=1.3$ ) for the live-bed scour condition by many researchers (see Whitehouse, 1998). Melville and Sutherland (1988) proposed a conservative design method for local scour depth around piers based on envelope curves to experimental data. Their method is basically a systematic reduction of the potential largest possible local scour depth, according to the scour regime, flow depth, sediment size, and shape of pier. As the effect of moving ripples on the equilibrium scour depth is not fully understood, which may bring a discrepancy in prediction of scour depth, it is recommended to use the deeper scour for design purposes (Zanke et al., 2011).

\subsection{Scour at pile foundation in wave-alone}

For scour around the pile under the action of waves alone, KeuleganCarpenter number is one of the main parameters governing the scouring process for the live-bed scour regime (see Kobayashi and Oda, 1994; Sumer et al., 1992). Keulegan-Carpenter number $(K C)$ is defined as

$K C=U_{w m} T / D$

where $U_{w m}$ is the maximum velocity of the undisturbed wave-induced oscillatory flow at the sea bottom above the wave boundary layer; $D$ is the pile diameter; $T$ is the wave period. However, for small values of $K C$ (such as $K C \approx O(10)$ ), the presence of the horseshoe vortex is quite limited in both space and time domains, and its influence on the scour is much less than that in steady currents $(K C \approx \infty)$. That is, with decreasing $K C$, the effect of horseshoe vortex decreases and that of the vortex shedding increases accordingly. An empirical expression for scour depth at a circular slender pile exposed to regular waves was established by Sumer et al. (1992):

$$
S / D \approx 1.3[1-\exp (-0.03(K C-6))] \text { for } K C \geq 6 \text {. }
$$

Note that the expression of Eq. (2) is valid for the live-bed conditions, which was confirmed by Kobayashi and Oda (1994).

Sumer et al. (2007) further investigated the effect of the soil density on the scour depth and the time scale of scour at a pile in waves. Sumer and Fredsøe (2001b) also made an experimental study on the steadystreaming flow and the scour process around a large vertical circular cylinder under waves. The flow is in the unseparated flow regime $(K C<O(1))$. The scour is found to depend mainly on $K C$ and the diffraction parameter $(D / L)$. The scour depth generally increases with these parameters.

Zanke et al. (2011) proposed a unifying formula by introducing a transition function $\left(x_{\text {rel }}=x_{\text {eff }} /\left(1+x_{\text {eff }}\right)\right)$ into Eq. (2), for the prediction of equilibrium scour depth around a pile under the action of waves, tidal or steady currents, i.e. $S / D=2.5\left(1-0.5 U_{c r} / U\right) x_{\text {rel }}$, where $S$ is the equilibrium scour depth at the pile, $x_{\text {eff }}=0.03\left(1-0.35 U_{c r} / U\right)$ (KC-6), $U$ is the mean velocity in case of steady currents, and $U_{c r}$ is the critical velocity for initiation of sediment motion, which can be calculated with $U_{c r}=1.4\left(2 \sqrt{\frac{\rho_{s}-\rho_{w}}{\rho_{w}}} g d+10.5 \mathrm{v} / d\right)$, in which $\rho_{s}$ is the sediment grain density, $\rho_{w}$ is the water density, $g$ is the gravitational acceleration, $d$ is the grain diameter, and $\nu$ is the kinematic viscosity of water.

For the scour region around a pile in waves, Umeda (2011) identified a variety of scour regimes according to the shape of the scour hole and ripple pattern. It was also noticed that, there exists substantial discrepancy among $K C$ data, even when the data were obtained in the same series of laboratory experiments.

\subsection{Scour at pile foundation under combined waves and current}

As illustrated in Fig. 1, the local scour around a pile under combined waves and current involves a complex interaction between waves, current, pile and its neighboring soil.

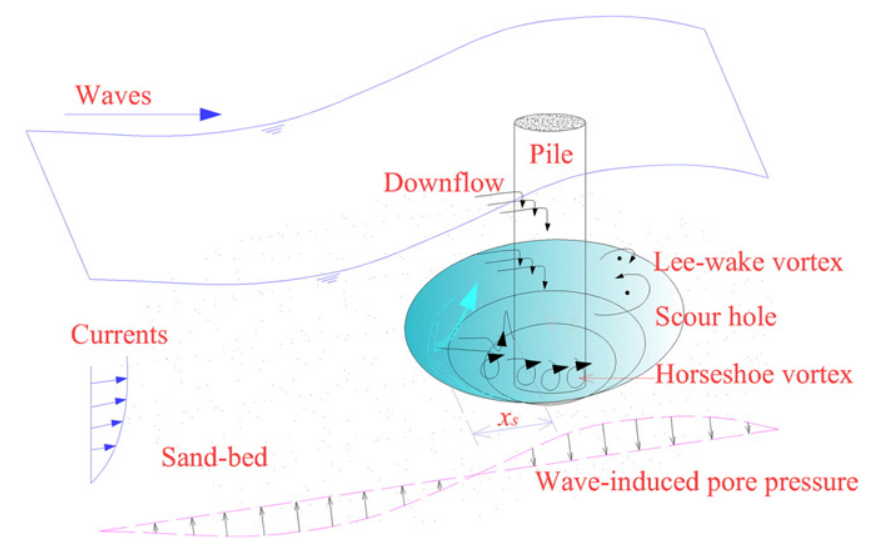

Fig. 1. Illustration of wave/current-pile-soil coupling process for the local scour around a monopile foundation.

When the waves and current coexist, the sediment is normally picked up by the waves due to its higher capacity of lifting sands and transported by the current due to its higher capacity of carrying sands. Nevertheless, the effect of waves and current's coexistence is more than just a superimposition of their capacities of initiating and carrying sediment due to a nonlinear interaction between waves and current within and outside the bottom boundary layer (Grant and Madsen, 1979; Kemp and Simons, 1982, 1983; Klopman, 1994; Olabarrieta et al., 2010). Furthermore, if a circular cylinder was mounted vertically on the flat wall in the combined current-wave flow, a threedimensional separation of the wave-current boundary layer flow will produce a complex time-dependent three-dimensional flow field around the base of a vertical monopile (Sumer et al., 1997), which controls the scouring process at the pile under combined waves and current.

When the combined current-wave flow is obstructed by a circular cylinder mounted vertically on the flat wall, the characteristics of the horseshoe vortex and wake vortex around the pile can be very different according to different current conditions and wave conditions compared with those under current-alone or wave-alone condition. To the author's knowledge, the only experimental investigation so far on the flow pattern around a vertical pile in a combined current-wave flow is made by Sumer et al. (1997). Their results showed that introducing a following current in the waves increases the size and lifespan of the horseshoe vortex, and lowers the critical $K C$ number for the threshold of horseshoe vortex. The horseshoe vortex exists for smaller $K C$ with increasing current-to-wave velocity ratio. This result is related to the increase in the adverse pressure gradient in front of the pile caused by the superimposed current.

Scouring at the pile foundation in combined waves and current is a complicated coupling process between fluid, structure and soil. The experimental results of Eadie and Herbich (1986) indicated that the scour development is faster and the equilibrium scour depth is greater under combined waves and current, compared with the case of current-alone. The scale and shape of the scour hole depend on the relative magnitude of the current velocity and the oscillatory flow velocities. Sumer and Fredsøe (2001a) conducted a series of tests of irregular waves propagating either with or perpendicular to the currents, indicating that the scour depth for combined waves and current is influenced by $K C$ and the ratio of velocities $\left(U_{c w}=U_{c}\right.$ / $\left(U_{c}+U_{w m}\right)$, in which $U_{c}$ represents the undisturbed near-bed current velocity component of the combined flow). The scour depth approaches an asymptotic value called steady-current value as $U_{c w}$ is larger than about 0.7. Rudolph and Bos (2006) carried out model tests on scour around a monopile under combined waves and current with oblique directions, focusing on the range $1<K C<10$. They proposed an improved scour depth prediction formula based on Sumer and Fredsøe (2002) by analyzing their new data and preceding data. 
Recently, Sumer et al. (2013) presented an experimental investigation of the scour holes backfilling under waves or combined waves and current around a pile. The results show that the scour depth corresponding to the equilibrium state of backfilling is the same as that corresponding to the equilibrium state of scour around the pile for the same wave or combined waves and current climate. The time scale of the scour around a pile in combined waves and current was studied by Petersen et al. (2012). The results indicate that three parameters (namely $U_{c w}, K C$, and the Shields number) govern the time scale.

As mentioned earlier, the equilibrium scour depth prediction is of great concern for the coastal and offshore foundations design. Based on Sumer and Fredsøe's (2001a) experimental data, Sumer and Fredsøe (2002) derived the following empirical expression for the scour depth under combined waves and current

$S / D=S_{c} / D\{1-\exp [-A(K C-B)]\}$ for $K C \geq B$

in which $S_{c}$ is the scour depth for the current-only case, and the parameters $A$ and $B$ are given as $A=0.03+0.75 U_{c w}^{2.6}$ and $B=$ $6 \exp \left(-4.7 U_{c w}\right)$, separately. Note that Eq. (3) is only valid for the case of live-bed scour regime with $K C$ in the range from 4 to 26 . The value of $S_{C} / D$ can be expressed with a mean value $S_{c} / D=1.3$ and a standard deviation $\sigma_{S / D}=0.7$. The maximum scour depth for the live-bed scour regime is suggested to take as $S_{c} / D=1.3+\sigma_{S / D}=2.0$ or $S_{c} / D=$ $1.3+2 \sigma_{S / D}=2.7$ for design purpose.

In most previous studies, the effect of wave-induced pore pressure in the soil was rarely taken into account. The wave-trough-induced pore pressure could exert an upward force onto the sand grains, making the incipient motion easier and sand-bed more vulnerable to scour, especially for the silty sand (Li et al., 2011), and finally affect the scour process.

In general, the controlling mechanism of the scour process and the equilibrium scour depth prediction around pile foundation in wavealone or in current-alone condition has been well established. Yet for the condition of combined waves and current, the physical mechanism for the scouring phenomenon has not been well understood.

In this study, a series of flume tests with low values of $K C$ number under wave-current combined conditions were conducted to reveal the wave/current-pile-sand coupling mechanism for the local scour around a monopile foundation. The scour depth, pore pressure, wave height and flow velocity were measured simultaneously. The effect of wave-current combination is examined by superimposing waves with various values of wave height on a following-current and opposing- current. Meanwhile, the pore pressure response around the monopile and its effect on the scour development are examined.

\section{Wave/current-pile-sand coupling experiments}

\subsection{Experimental set-up}

The experiments were conducted in a flow-structure-soil interaction flume (52 m long, $1 \mathrm{~m}$ wide and $1.5 \mathrm{~m}$ high) newly constructed at the Institute of Mechanics, Chinese Academy of Sciences. The flume is capable of synchronously generating waves and current. A piston-type wave generator is located at the upstream end and a porous plastic type sloped wave absorber at the downstream end to handle wave reflection. While producing either regular waves or irregular waves, this flume is capable of generating reversible steady flow with velocity up to around $0.6 \mathrm{~m} / \mathrm{s}$ at $0.5 \mathrm{~m}$ water depth meanwhile. As illustrated in Fig. 2, a specially designed large soil-box $(6.0 \mathrm{~m}$ in length, $1.8 \mathrm{~m}$ in depth and $1.0 \mathrm{~m}$ in width) is located in the middle section of the flume, and a segment of $2.0 \mathrm{~m} \times 0.5 \mathrm{~m} \times 1.0 \mathrm{~m}$ (length $\times$ depth $\times$ width) was employed in this series of experiments.

Local scour at the upstream edge due to the small length of the test section occurred only in the tests with a comparatively large maximum value of the combined waves and current velocity. The influence of the ripples induced by the upstream edge scour on the scour depth is very limited due to a relatively large value of scour depth produced by the comparatively large value of the combined waves and current velocity, compared with the value of ripple's height.

A saturated sand-bed was adopted to simulate a sandy seabed, whose main physical properties are listed in Table 1. Two Perspex cylindrical model piles with diameters $D=0.20 \mathrm{~m}$ and $0.08 \mathrm{~m}$ were used, respectively. The model pile was vertically installed at the central point of the soil box.

Far-field wave height was measured synchronously with two wave height gauges at two points with a $0.5 \mathrm{~m}$ gap along the central line at the distance of $15 \mathrm{~m}$ apart from the pile. Thus the wave length could be calculated using the Goda's two-point method. Other two wave height gauges were located just above the pore pressure sensors with the distances of $30 \mathrm{~cm}$ and $50 \mathrm{~cm}$ apart from the pile center along the central line, respectively. An Acoustic Doppler Velocimetry (ADV) was mounted to measure the undisturbed flow velocity at the level of $1.0 D$ above the sand-bed at the distance of $20 \mathrm{~m}$ apart from the pile center. Two ultrasonic distance sensors were fixed vertically in the water at the upstream-face and the side-face of the pile separately to measure the development of the scour depth. Ten GE Druck miniature pore-

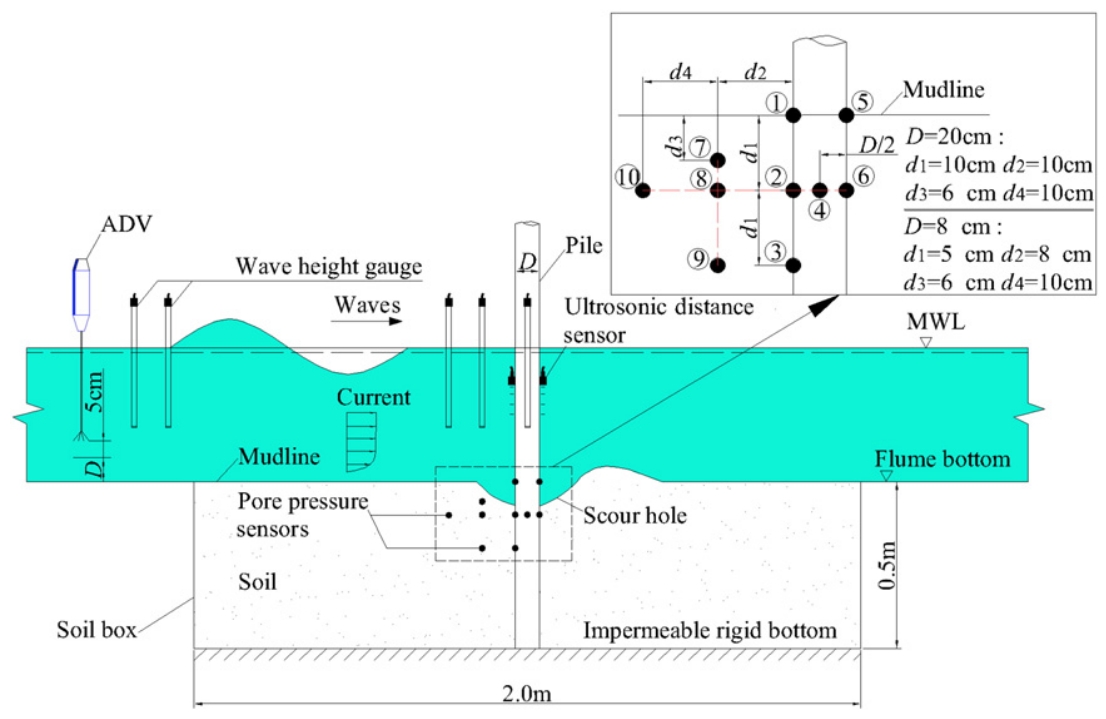

Fig. 2. Schematic diagram of the experimental system. 
Table 1

Index properties of test sands.

\begin{tabular}{llllll}
\hline $\begin{array}{l}\text { Mean size of } \\
\text { sand grains }\end{array}$ & $\begin{array}{l}\text { Geometric standard } \\
\text { deviation }\end{array}$ & $\begin{array}{l}\text { Coefficient of } \\
\text { permeability }\end{array}$ & $\begin{array}{l}\text { Void } \\
\text { ratio }\end{array}$ & $\begin{array}{l}\text { Relative } \\
\text { density }\end{array}$ & $\begin{array}{l}\text { Buoyant unit } \\
\text { weight of soil }\end{array}$ \\
\hline $\begin{array}{c}d_{50} \\
(\mathrm{~mm})\end{array}$ & $\sigma_{g}$ & $\begin{array}{l}k_{s} \\
(\mathrm{~m} / \mathrm{s})\end{array}$ & $e$ & $D_{r}$ & $\gamma^{\prime}$ \\
0.38 & 1.28 & $1.88 \times 10^{-4}$ & 0.771 & 0.352 & 9.03 \\
\hline
\end{tabular}

pressure sensors were utilized to measure the wave-induced pore water pressure in the surrounding sands. The arrangement of the pore-pressure sensors is detailed in Fig. 2 (filled circles in the top right corner of Fig. 2). A topographic meter consisted of 15 ultrasonic distance sensors and a laser displacement transducer was designed and utilized to obtain the 3-D topographic details of the local scour around the model pile.

The signals of wave height gauges and pore pressure sensors were multichannel synchronous sampled via the NI USB-6255 Data Acquisition Card. Moreover, the phenomenon of the scour development was recorded with a camera through the transparent glass wall of the flume.

\subsection{Test conditions}

Test conditions and scour measurements are summarized in Table 2 for current alone and current with following waves, and Table 3 for current with opposing waves. The water depth $(h)$ was kept constant at $0.5 \mathrm{~m}$. Regular waves were adopted to conveniently analyze the pore-pressure responses and orbital velocities of the flow. Low $K C$ number conditions are more common in the practice and related study for waves-current combined condition is scarce. Thus the $K C$ numbers in the present experiments lies in the range 0 to 4 .

The quantities $U_{c}$ and $U_{w m}$ in Tables 2 and 3 are individually the velocity of the current component and orbital component of the undisturbed combined flow, measured at the level of $1.0 \mathrm{D}$ above the sand-bed, representing the characteristic flow velocity at the boundary layer. The pile Reynolds number ( $\mathrm{Re})$ is defined as

$\operatorname{Re}=U_{m} D / \nu$ in which $U_{m}\left(=U_{c}+U_{w m}\right)$ is the maximum value of the combined waves and current velocity at the level of $1.0 \mathrm{D}$ above the sand-bed. The Shields parameter $(\theta)$ is defined as

$\theta=\frac{U_{f}^{2}}{g\left(\rho_{s} / \rho_{w}-1\right) d_{50}}$

in which $U_{f}$ is the maximum value of the undisturbed friction velocity. The detailed calculation procedure of $\theta$ under combined waves and current is given by Soulsby (1997). The critical Shields parameter for the sediment initiation on the bed can be calculated with (Soulsby, 1997):

$\theta_{c r}=\frac{0.3}{1+1.2 D_{*}}+0.055\left[1-\exp \left(-0.02 D_{*}\right)\right]$

in which $D_{*}=d_{50}\left[(s-1) g / v^{2}\right]^{1 / 3}$ is known as the dimensionless grain size. For the present examined medium sand-bed the value of $\theta_{c r}$ is 0.036 . As shown in Tables 2 and 3, the live-bed scour regime prevailed in the present experiments except runs 1,5 and 9.

No sediment nourishment was provided upstream of the test section. The effect has been examined carefully. The sand washed out of the test section in runs 19 and 25 was collected after the tests. The volumes of the sand washed out of the test section were $3.84 \mathrm{l}$ (4.85 l) in run 19 (run 25). Thus the general lowering of the sand bed level due to the erosion of the sediment from the test section was about $1.9 \mathrm{~mm}(2.4 \mathrm{~mm}$ ) in run 19 (run 25). The duration of run 19 (run 25) is approximately $2 \mathrm{~h}(3 \mathrm{~h})$. Thus the net sediment erosion from the test section made a contribution to the scouring rate by $0.95 \mathrm{~mm} / \mathrm{h}$ $(0.8 \mathrm{~mm} / \mathrm{h})$ in run 19 (run 25), which can be considered negligible compared with the relatively rapid scouring rate under the corresponding live-bed condition.

\subsection{Testing procedure}

In general, the testing procedure was adopted as follows:

(1) The flume including the soil box was firstly emptied and cleaned. The pore pressure sensors were soaked and deaired to ensure their argil-covers being free of air. They were then installed at the specific locations with the support of a rack, and the model pile was fixed in the middle of the soil box (see Fig. 2).

Table 2

Test results for local scour around a pile: Current alone and current with following waves.

\begin{tabular}{|c|c|c|c|c|c|c|c|c|c|c|c|c|}
\hline Run number & $\begin{array}{l}D \\
(\mathrm{~m})\end{array}$ & $\begin{array}{l}H \\
(\mathrm{~m})\end{array}$ & $\begin{array}{l}T \\
(\mathrm{~s})\end{array}$ & $\begin{array}{l}U_{c} \\
(\mathrm{~m} / \mathrm{s})\end{array}$ & $\begin{array}{l}U_{w m} \\
(\mathrm{~m} / \mathrm{s})\end{array}$ & $\begin{array}{l}U_{m} \\
(\mathrm{~m} / \mathrm{s})\end{array}$ & $U_{c w}$ & $\theta$ & $K C$ & $\operatorname{Re}$ & $S / D$ & $R_{S}$ \\
\hline 1 & 0.20 & 0 & 1.4 & 0.15 & 0 & 0.15 & 1 & 0.008 & - & $2.21 \times 10^{4}$ & 0 & 1 \\
\hline 2 & 0.20 & 0.043 & 1.4 & 0.15 & 0.068 & 0.218 & 0.69 & 0.036 & 0.48 & $3.21 \times 10^{4}$ & 0.025 & / \\
\hline 3 & 0.20 & 0.097 & 1.4 & 0.15 & 0.137 & 0.287 & 0.52 & 0.075 & 0.96 & $4.22 \times 10^{4}$ & 0.075 & / \\
\hline 4 & 0.20 & 0.145 & 1.4 & 0.15 & 0.201 & 0.351 & 0.43 & 0.125 & 1.41 & $5.16 \times 10^{4}$ & 0.11 & / \\
\hline 5 & 0.20 & 0 & 1.4 & 0.23 & 0 & 0.23 & 1 & 0.02 & - & $3.38 \times 10^{4}$ & 0.2 & 1.19 \\
\hline 6 & 0.20 & 0.026 & 1.4 & 0.23 & 0.063 & 0.293 & 0.78 & 0.036 & 0.44 & $4.31 \times 10^{4}$ & 0.27 & 1.06 \\
\hline 7 & 0.20 & 0.052 & 1.4 & 0.23 & 0.107 & 0.337 & 0.68 & 0.054 & 0.75 & $4.96 \times 10^{4}$ & 0.34 & 1.05 \\
\hline 8 & 0.20 & 0.085 & 1.4 & 0.23 & 0.156 & 0.386 & 0.6 & 0.078 & 1.09 & $5.68 \times 10^{4}$ & 0.44 & 1.13 \\
\hline 9 & 0.08 & 0 & 1.4 & 0.23 & 0 & 0.23 & 1 & 0.021 & - & $1.35 \times 10^{4}$ & 0.39 & 1.03 \\
\hline 10 & 0.08 & 0.033 & 1.4 & 0.23 & 0.073 & 0.303 & 0.76 & 0.045 & 1.28 & $1.78 \times 10^{4}$ & 0.65 & 1.18 \\
\hline 11 & 0.08 & 0.068 & 1.4 & 0.23 & 0.126 & 0.356 & 0.65 & 0.07 & 2.21 & $2.09 \times 10^{4}$ & 0.84 & 0.95 \\
\hline 12 & 0.08 & 0.103 & 1.4 & 0.23 & 0.173 & 0.403 & 0.57 & 0.104 & 3.03 & $2.37 \times 10^{4}$ & 1 & 0.98 \\
\hline 13 & 0.08 & 0 & 1.4 & 0.34 & 0 & 0.34 & 1 & 0.049 & - & $2.00 \times 10^{4}$ & 1.15 & 1.02 \\
\hline 14 & 0.08 & 0.098 & 1.4 & 0.34 & 0.157 & 0.497 & 0.68 & 0.124 & 2.75 & $2.92 \times 10^{4}$ & 1.26 & 1.19 \\
\hline 15 & 0.20 & 0 & 1.4 & 0.34 & 0 & 0.34 & 1 & 0.049 & - & $5.00 \times 10^{4}$ & 0.62 & 1.18 \\
\hline 16 & 0.20 & 0.057 & 1.4 & 0.34 & 0.104 & 0.444 & 0.77 & 0.075 & 0.73 & $6.53 \times 10^{4}$ & 0.67 & 1.10 \\
\hline 17 & 0.20 & 0.092 & 1.4 & 0.34 & 0.140 & 0.48 & 0.71 & 0.104 & 0.98 & $7.06 \times 10^{4}$ & 0.65 & 1.14 \\
\hline 18 & 0.08 & 0.108 & 1.8 & 0.20 & 0.117 & 0.317 & 0.63 & 0.066 & 2.63 & 18,647 & 0.73 & 1.03 \\
\hline 19 & 0.08 & 0.112 & 1.8 & 0.22 & 0.129 & 0.349 & 0.63 & 0.077 & 2.90 & 20,529 & 0.70 & 1.00 \\
\hline 20 & 0.08 & 0.056 & 1.8 & 0.26 & 0.087 & 0.347 & 0.75 & 0.065 & 1.96 & 20,412 & 1 & 1.02 \\
\hline 21 & 0.08 & 0.084 & 2.0 & 0.107 & 0.090 & 0.197 & 0.54 & 0.039 & 2.25 & 11,588 & 0.33 & 1.10 \\
\hline
\end{tabular}


Table 3

Test results for local scour around a pile: Current with opposing waves.

\begin{tabular}{|c|c|c|c|c|c|c|c|c|c|c|c|c|}
\hline Run number & $\begin{array}{l}D \\
(\mathrm{~m})\end{array}$ & $\begin{array}{l}H \\
(\mathrm{~m})\end{array}$ & $\begin{array}{l}T \\
(\mathrm{~s})\end{array}$ & $\begin{array}{l}U_{c} \\
(\mathrm{~m} / \mathrm{s})\end{array}$ & $\begin{array}{l}U_{w m} \\
(\mathrm{~m} / \mathrm{s})\end{array}$ & $\begin{array}{l}U_{m} \\
(\mathrm{~m} / \mathrm{s})\end{array}$ & $U_{c w}$ & $\theta$ & $K C$ & $\operatorname{Re}$ & $S / D$ & $R_{S}$ \\
\hline 22 & 0.08 & 0.152 & 1.4 & 0.2 & 0.136 & 0.336 & 0.6 & 0.086 & 2.38 & $1.98 \times 10^{4}$ & 0.76 & 1.07 \\
\hline 23 & 0.08 & 0.14 & 1.4 & 0.23 & 0.141 & 0.371 & 0.62 & 0.08 & 2.47 & $2.12 \times 10^{4}$ & 0.78 & 1.05 \\
\hline 24 & 0.08 & 0.138 & 1.8 & 0.18 & 0.162 & 0.342 & 0.53 & 0.091 & 3.65 & $2.01 \times 10^{4}$ & 0.73 & 1.05 \\
\hline 25 & 0.08 & 0.082 & 1.8 & 0.274 & 0.122 & 0.396 & 0.69 & 0.084 & 2.75 & $2.33 \times 10^{4}$ & 1.03 & 1.02 \\
\hline 26 & 0.08 & 0.102 & 2.0 & 0.109 & 0.144 & 0.253 & 0.43 & 0.063 & 3.6 & $1.49 \times 10^{4}$ & 0.25 & 1.10 \\
\hline 27 & 0.08 & 0.086 & 2.0 & 0.21 & 0.111 & 0.321 & 0.65 & 0.063 & 2.78 & $1.89 \times 10^{4}$ & 0.75 & 1.02 \\
\hline 28 & 0.20 & 0.129 & 1.4 & 0.22 & 0.140 & 0.360 & 0.61 & 0.057 & 0.98 & $1.91 \times 10^{4}$ & 0.29 & 1.17 \\
\hline
\end{tabular}

(2) The soil box was whereafter filled with clean water to a certain depth. The sand bed was carefully prepared by means of sandraining technique. The surface of the sand bed was leveled off smoothly with a scraper.

(3) The flume was then filled slowly with water to a given depth (e.g. $0.5 \mathrm{~m}$ ).

(4) Both the wave maker and the current generator were switched on to generate waves and current concurrently.

(5) The multichannel synchronous sampling system was then started to measure the multi-physics parameters, e.g. wave height, pore pressure, flow velocity, and scour depth.

\section{Results and discussions}

\subsection{Effects of superimposing waves on a current}

Fig. 3(a) gives a comparison of different time series of pore-pressure $p_{1}$ for various values of wave height. It is indicated that the regular wave-induced instantaneous pore pressure at the interfacial of the pile and the sand-bed $\left(p_{1}\right)$ presents a sinusoidal variation. Fig. 3(b) gives a comparison of different time series of flow velocity at the level of $1.0 \mathrm{D}$ above the sand-bed under various values of wave height. As shown in Fig. 3(b), the flow velocity is changing periodically and the maximum value of the periodic velocity reaches $U_{m}=0.4 \mathrm{~m} / \mathrm{s}$ for the superimposed waves with $H=8.5 \mathrm{~cm}$. The periodic variation of flow velocity also enhances the vortex-shedding at the downstream side of the pile, which accelerates the sand grains transporting around the pile and makes a difference on the scour profile between under waves with a current and under current alone.

In general, as waves are superimposed onto a current, there mainly exist two effects: one is to enlarge the flow velocity periodically, so as to increase the shear-stress on the surface of the sand-bed, which make the grains more vulnerable to the motion initiation; the other is to exert upward seepage force onto the sand grains under the series of wave troughs, which is also beneficial to the bed mobility.

\subsection{Time development of scour depth}

3.2.1. Case of regular waves with current: Clear-water scour regime under current alone $\left(U_{c}=0.23 \mathrm{~m} / \mathrm{s}\right)$

The scour regime is in clear-water regime under current-alone with $U_{c}=0.23 \mathrm{~m} / \mathrm{s}$ due to a smaller $\theta$ value than the critical Shields parameter (see run 5 in Table 2). After superimposing waves even with small wave height on the current, the scour regime turns into live-bed regime immediately (see runs 6-8 in Table 2). Fig. 4(a) and (b) gives two series of scour depth developments at the upstream edge of the model pile for $D=0.20 \mathrm{~m}$ and $0.08 \mathrm{~m}$ respectively, showing the effect of superimposing waves with various wave heights $(T=$ $1.4 \mathrm{~s})$ onto the current $\left(U_{c}=0.23 \mathrm{~m} / \mathrm{s}\right)$.

It is indicated that none of the tests in Fig. 4 have reached equilibrium. Melville and Chiew (1999) reported that in order to achieve equilibrium conditions in small-scale laboratory experiments, it was necessary to conduct experiment for several days. Sheppard et al. (2004) applied a four-parameter exponential function for extrapolation of the equilibrium scour depth $(S)$ from scour depth development versus time $(t)$ :

$S_{t}=a[1-\exp (-b t)]+c[1-\exp (-d t)]$

where $S_{t}$ is the scour depth corresponding to $t ; a, b, c$, and $d$ are coefficients obtained from least square fit to data. We have used Eq. (7) for extrapolation of $S_{t}$ as a function of $t$ to obtain $S$.

Fig. 5 shows the comparison of $S_{t}$ as a function of $t$ with that obtained using equation for runs 8 and 15 , respectively. Note that the commencement time for local scour at the upstream side of the pile $(t>0$; filled triangle in Fig. 4(a)) doesn't coincide with the test starting time (i.e. $t=0$ ). The scour depth development curves versus time are translated to be zeroaxial to provide reasonable extrapolations. In general,

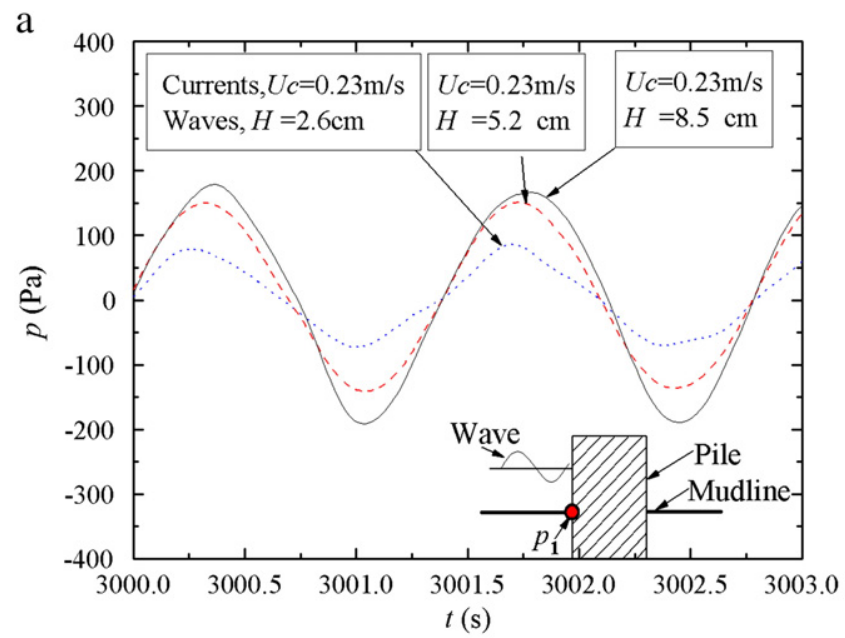

b

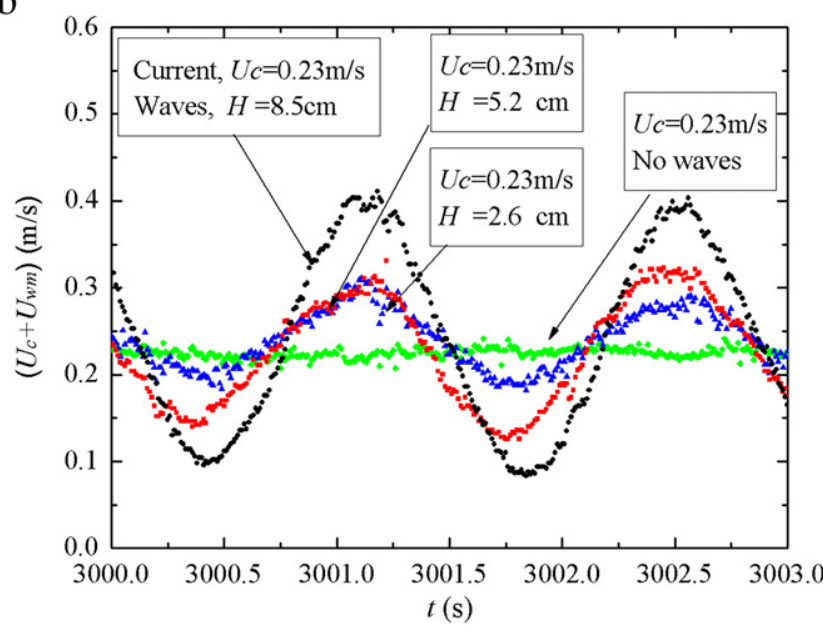

Fig. 3. Comparisons of: (a) pore-pressure profiles measured with sensor $1\left(p_{1}\right)$; (b) measured velocity at the level of $1.0 \mathrm{D}$ above the sand-bed for various values of wave height $\left(U_{c}=0.23 \mathrm{~m} / \mathrm{s}, T=1.4 \mathrm{~s}, D=0.20 \mathrm{~m}\right)$. 
a

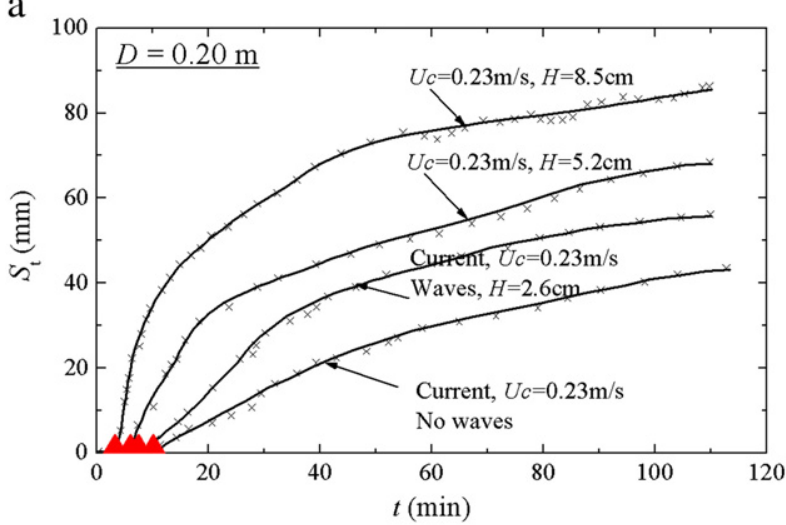

b

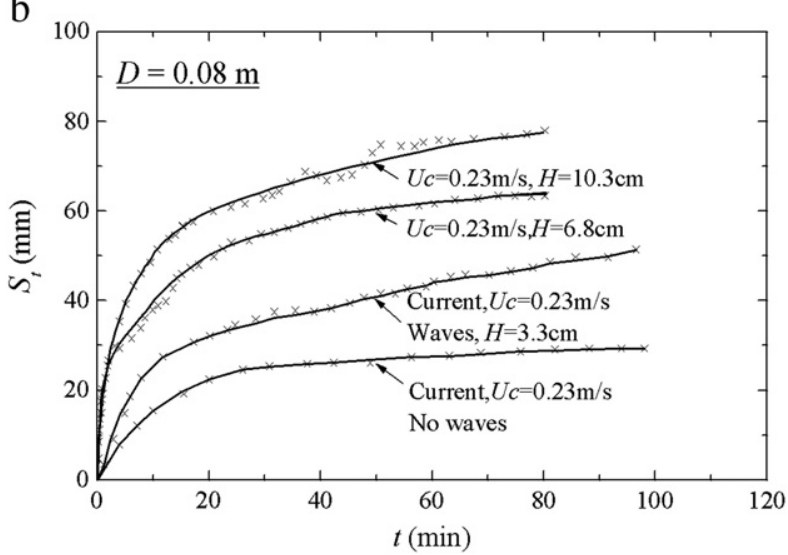

Fig. 4. Time development of scour depth measured at upstream edge of pile under waves with various wave heights following a current with a constant velocity $U_{c}=0.23 \mathrm{~m} / \mathrm{s}$ (clearwater scour regime under current alone): (a) $D=0.20 \mathrm{~m}$, runs $5-8$; (b) $D=0.08 \mathrm{~m}$, runs 9-12.

the ratio of the extrapolated $(t=\infty)$ and observed maximum scour depths $\left(R_{S}=S_{\text {extrapolated }} / S_{\text {observed }}\right)$ was less than 1.2 for all runs except in runs 1-4 where the scour depth developments were not captured due to small scour depths (see Tables 2 and 3). However, $S_{\text {observed }}$ at time $t=100 \mathrm{~min}$ was used as $S$ instead of $S_{\text {extrapolated }}$ in the analysis of results (refer to Debnath and Chaudhuri (2010)). Scour depths of a few runs with duration less than 100 min were obtained by extrapolating the measured experimental data. It may be useful to

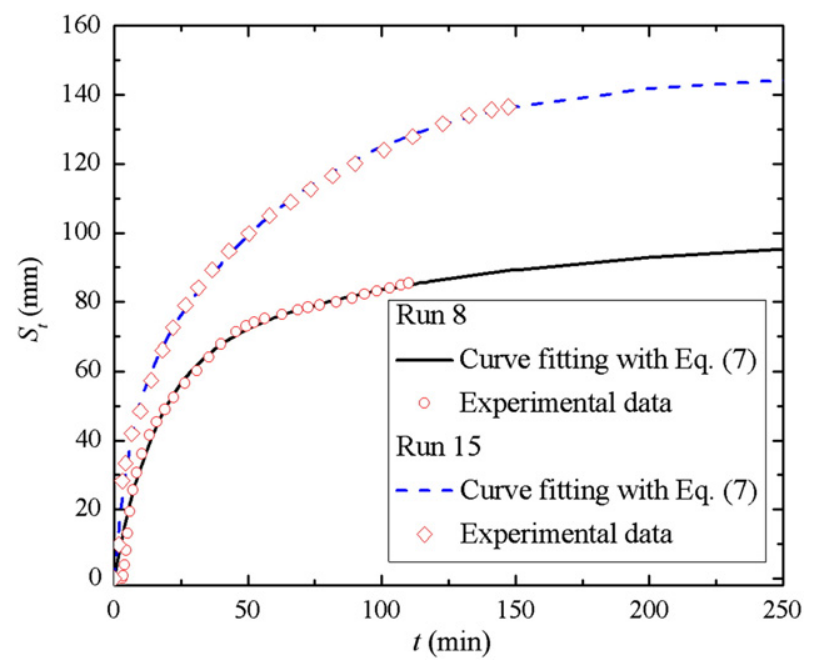

Fig. 5. Curve fit to measured scour depth development data. multiply the estimated $S_{\text {observed }}$ by a factor of 1.2 for obtaining safe estimates of equilibrium scour depth for design purpose.

As shown in Fig. (4), a rapid development of the local scour depth occurs at the initial scouring stage. Then the scouring rate decreases more tardily until the equilibrium state is reached. Note that the solid lines in Fig. 4 are smooth approaches to the original data marked with crosses. Experimental observation also shows that sand ripples were formed while the waves with relatively greater wave height (e.g. $H=$ $8.5 \mathrm{~cm}$ in Fig. 4(a) and $H=10.3 \mathrm{~cm}$ in Fig. 4(b)) were superimposed on the current, which resulted in a fluctuation of the scour depth as the sand waves propagate through the local scour zone around the model pile.

Comparison between these series of the time development of scour depth indicates that the rate of scour depth development under waves with current is remarkably faster than that under current alone, and the equilibrium scour depth is greater than a linear superposition of those under waves and current separately (e.g. approximately 3 times of that under current alone, see Fig. 4). This is mainly attributed to the scour-regime turning from clear-water to live-bed which resulted from superimposing waves. The phenomena mentioned above are displayed clearly and visually in Fig. 6 .

Comparing Fig. 4(a) with Fig. 4(b) (along with Fig. 6(a) and (b)), it can be seen that the rate of scour depth development with pile diameter $D=0.20 \mathrm{~m}$ is smaller than that with pile diameter $D=0.08 \mathrm{~m}$, i.e. more time is needed to reach the final equilibrium state in the case of pile diameter $D=0.20 \mathrm{~m}$ than the case of $D=0.08 \mathrm{~m}$. It is indicated in Fig. 4(a) that the commencement time for local scour at the upstream side of the pile (filled triangle in Fig. 4(a)) doesn't coincide with the test
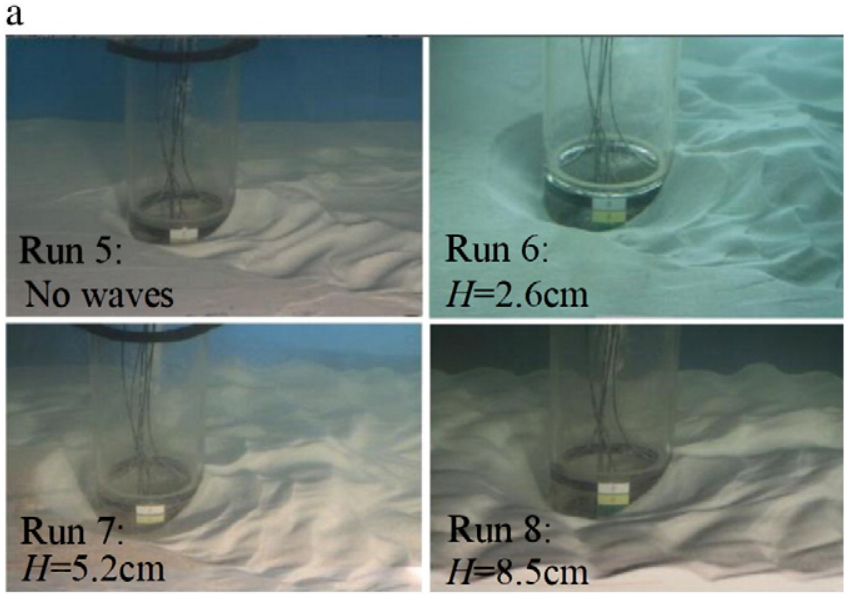

b
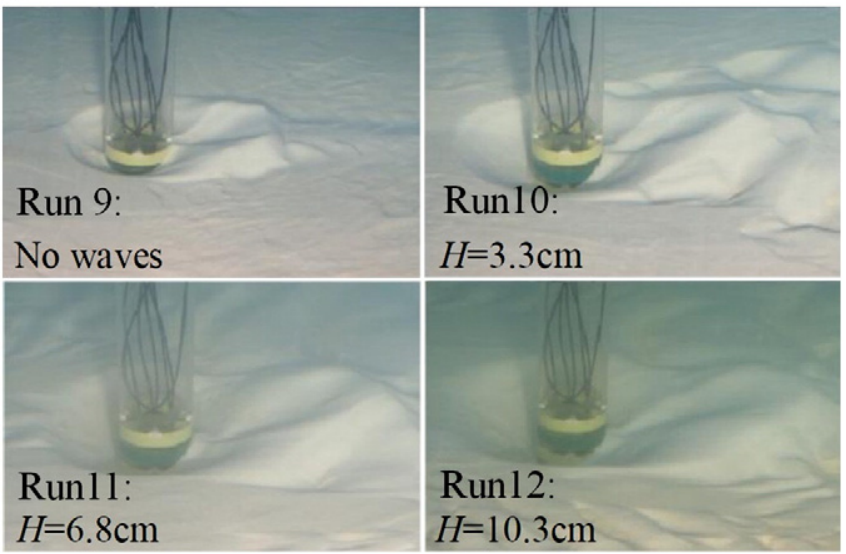

Fig. 6. Scour holes under waves with various wave heights following a current with a constant velocity $U_{c}=0.23 \mathrm{~m} / \mathrm{s}$ (clear-water scour regime under current alone): (a) $D=0.20 \mathrm{~m}$; (b) $D=0.08 \mathrm{~m}$. 
starting time (i.e. $t=0$ ). Test observation shows that the local scour around the large-diameter model pile (e.g. $D=0.20 \mathrm{~m}$ ) was triggered firstly from the lateral sides of the pile with two small scour holes, which then extended towards the upstream and downstream sides of the pile. Nevertheless, for the model pile with relatively smaller diameter (e.g. $D=0.08 \mathrm{~m}$ ), the local scour triggered from the lateral sides of the pile extended rapidly to the upstream and downstream sides of the pile (usually 5 to $20 \mathrm{~s}$ in the tests, see Fig. 4(b)). Thus, the commencement time for local scour at the upstream side of the pile $\left(t_{s} \approx 0\right)$ coincides with the test starting time, i.e. the time effect of local scour extending along the circumference of the pile is ignorable for the small-diameter piles.

3.2.2. Case of regular waves with current: Live-bed scour regime under current alone $\left(U_{c}=0.34 \mathrm{~m} / \mathrm{s}\right)$

It would be interesting to examine the effect on the scour of superimposing waves with various wave heights $(T=1.4 \mathrm{~s})$ onto a current with a higher velocity $\left(U_{c}=0.34 \mathrm{~m} / \mathrm{s}\right)$, under which condition the live-bed scour condition prevails.

A series of scour depth developments at upstream edge of the pile with $D=0.20 \mathrm{~m}$ and $0.08 \mathrm{~m}$ are given in Fig. 7. Fig. 8 shows the scour holes at equilibrium state around a pile $(\mathrm{D}=0.08 \mathrm{~m})$ for various loading conditions. The rate of scour depth development under waves with a current is slightly faster and the equilibrium scour depth gets a little bigger than that under a current alone. In Fig. 4, while the current velocity was kept constant $U_{c}=0.23 \mathrm{~m} / \mathrm{s}$ and no waves were imposed, the sand-bed was in clear-water regime $(\theta \sim O(0.02))$. In Fig. 7, while the current velocity was kept $U_{c}=0.34 \mathrm{~m} / \mathrm{s}$ and no waves were imposed, the sand-bed was in the live-bed regime $(\theta \sim 0(0.05))$. A comparison between Figs. 4 and 7 indicates that the effect of superimposing waves onto a current under which the live-bed condition prevails (see Fig. 7) is not as obvious as that under which the clear-water condition prevails (see Fig. 4). The cyclic loading by the waves has much less influence on the scour depth under live-bed conditions than that under clear-water conditions.

\subsection{Correlation between pore-pressure and scour development}

Fig. 9 gives the variations of time-dependent scour depth $S_{t}$ and the amplitudes of $p_{2}, p_{3}$ and $\left(p_{2}-p_{3}\right)$ in run 8 with the loading time $t$. Note that the pore-pressure sensor- 2 and sensor- 3 were beneath the sand-bed surface during the whole testing time, as $S_{t}$ was less than $0.1 \mathrm{~m}$ during the whole scouring process. The amplitudes of $p_{2}, p_{3}$ and $\left(p_{2}-p_{3}\right)$ scatter within a pressure range about $25 \mathrm{~Pa}$, which may result from the vortex-induced pressure pulsation around the local scour hole. The approach lines of $p_{2}, p_{3}$ and $\left(p_{2}-p_{3}\right)$ using linear fitting method are also given in Fig. 9. With increasing scour depth $\left(S_{t}\right)$, the amplitudes

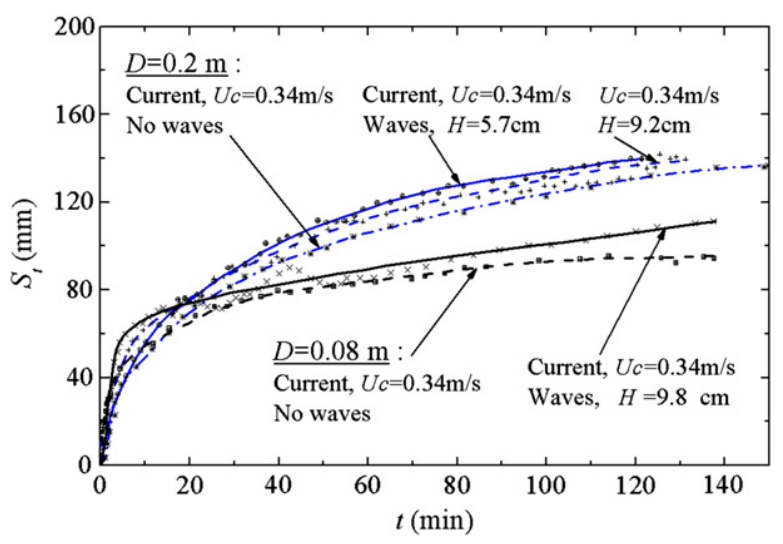

Fig. 7. Time development of scour depth measured at upstream edge of pile under waves with various wave heights following a current with a constant velocity $U_{c}=0.34 \mathrm{~m} / \mathrm{s}$ (live-bed scour regime under current alone, runs 13-17).

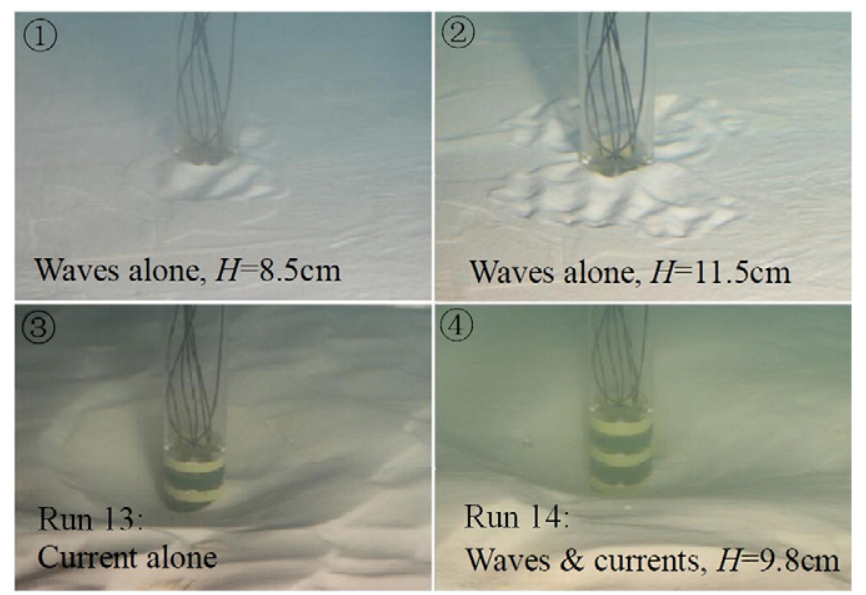

Fig. 8. Scour holes around a pile $(D=0.08 \mathrm{~m})$ for various loading conditions: 1 waves alone $(H=8.5 \mathrm{~cm}) ; 2$ waves alone $(H=11.5 \mathrm{~cm}) ; 3$ current alone $\left(U_{c}=0.34 \mathrm{~m} / \mathrm{s}\right) ; 4$ current with waves $\left(U_{c}=0.34 \mathrm{~m} / \mathrm{s}, H=9.8 \mathrm{~cm}\right)$.

of $p_{2}$ and $p_{3}$ tend to increase slowly and the corresponding amplitude of $\left(p_{2}-p_{3}\right)$ also increases.

The momentary soil liquefaction is generated by the seepage flow arising through the void of the soil skeleton, induced by the vertical gradient of the oscillating pore pressure near the bed surface. The body force on the soil skeleton is the seepage force and the self-weight of the soil particle, expressed as $j_{z}-\frac{1+2 K_{0}}{3} \gamma^{\prime}$, in which $j_{z}=\partial p^{\prime} / \partial z$ is the seepage force, the vertical upward direction is taken as the positive direction, and $p^{\prime}$ is the pore pressure variation in the soil. In the wave trough area, $j_{z}$ has a positive sign, exerting an upward force on the top layer of the soil. To take the effect of the upward seepage force on the pile scour process into consideration, a non-dimensional parameter named liquefaction index $\left(I_{L}\right)$ can be defined as

$I_{L}=j_{z} /\left(\frac{1+2 K_{0}}{3} \gamma^{\prime}\right)$

where $I_{L}$ is the ratio of the unit body force exerted by upward seepage flow and the average effective geostatic stress. No upward seepage is formed for the condition $I_{L}=0$, while the sand grains totally lose contact with each other and the seabed becomes momentarily liquefied for the condition $I_{L} \geq 1$. The greater the value of $I_{L}$, the smaller the drag force needed to initiate the sand grains. Thus under the condition with a relatively big value of $I_{L}$, enhancement of the scour depth development should be observed.

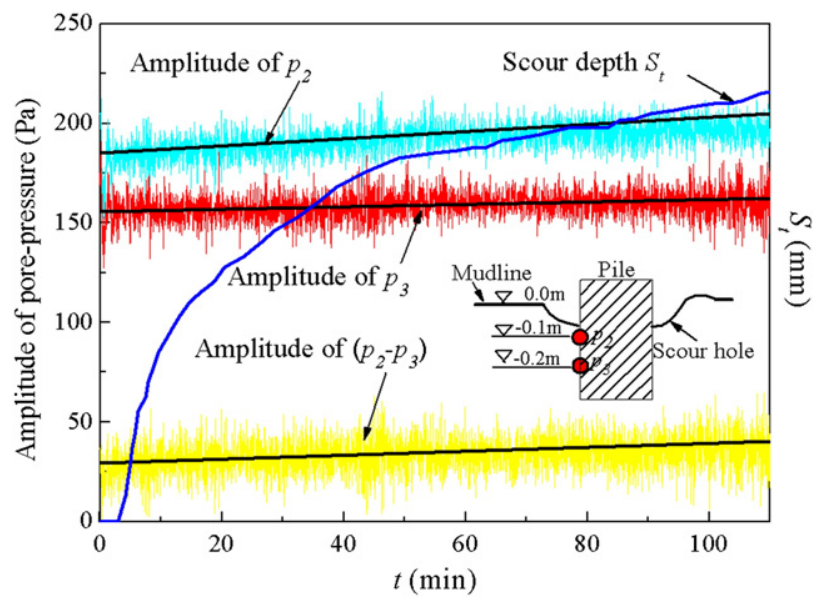

Fig. 9. Correlation between the wave-induced pore-pressure and the local scour development (run 8: $U_{c}=0.23 \mathrm{~m} / \mathrm{s}, H=8.5 \mathrm{~cm}, T=1.4 \mathrm{~s}, D=0.20 \mathrm{~m}, D_{r}=0.352$ ). 
In Fig. 9, the amplitude of $\left(p_{2}-p_{3}\right)$ is less than $40 \mathrm{~Pa}$, inducing an upward seepage (pore pressure gradient) with the magnitude of about $7 \%$ of the average effective geostatic stress $\left(1+2 K_{0}\right) \gamma^{\prime} z / 3$, i.e. $I_{L}=0.07$ at the position $z \approx-0.15 \mathrm{~m}$ of the upstream pile side, much less than 1 . So the effect of the wave-induced upward seepage on the scour development is not obvious in the present experiments.

Sakai et al.'s (1992) analysis implied that the parameter $\frac{k_{s} G}{\rho_{w^{2}} T h}$ is a controlling parameter influencing the wave-induced transient pore pressure response in the soil. Generally, $T$ and $h$ are approximately one order of magnitude smaller in the experiment conditions than in real sea states, and the value of the permeability coefficient $k_{s}$ of the examined sand-bed is basically at the same order as that of the medium sand in the field, producing a two orders smaller value of $\frac{k_{s} G}{\rho_{w} g^{2} T h}$ in the experiment conditions. This scale effect makes it difficult to reproduce the momentary liquefaction in the experiment conditions.

The possibility of soil liquefying could increase considerably due to air entrainment (Gratiot and Mory, 2000). The degree of saturation $\left(S_{r}\right)$ affects the apparent bulk modulus of elasticity of water $\left(K^{\prime}\right)$. The relationship between $S_{r}$ and $K^{\prime}$ is expressed as $\frac{1}{K^{\prime}}=\frac{1}{K}+\frac{1-S_{r}}{p_{\text {w0 }}}$, where $K$ is the true bulk modulus of elasticity of water and $p_{\mathrm{wo}}$ is the absolute pore-water pressure. $K^{\prime}$ decreases rapidly due to the existence of a small amount of gas. The soil in the present experiments was prepared carefully by means of sand-raining technique. This soil preparation process allowed the sand grains to deposit freely and get fully in touch with water, producing highly saturated soil, which makes it more difficult for the soil to liquefy.

It might be inferred that for the case of silty sand, whose permeability coefficient value is approximately one to two orders smaller than the medium sand in the present experiment, with the addition of greater wave height or a certain percentage of air entrainment in the soil, larger $I_{L}$ could be induced. In this condition, the pore pressure response could have obvious influence on the local scouring process.

\subsection{Influence of wave propagating direction relative to the current on scour process}

Fig. 10 gives the time development of scour depths at the upstream pile edge concerning waves following and opposing a current. Note that due to the reversal of the current direction, the specific locating side of the aforementioned upstream pile edge is just opposite to each other in tests with different angles between waves and current (between runs 12 and 23, runs 8 and 28; see Fig. 11). The set values of wave parameters $(H$ and $T)$ and current parameters $\left(U_{c}\right)$ in runs 12 and 23 are identical and so are those in runs 8 and 28. As shown in Fig. 10, the scour depth development for the opposing-current case is slower

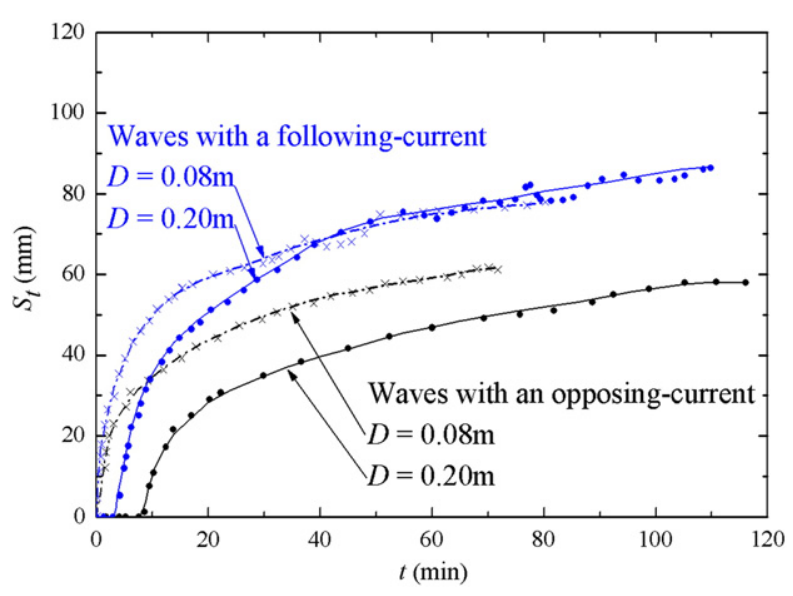

Fig. 10. Comparison of scour depth developments between the conditions of waves with a following-current and waves with an opposing-current. Live-bed scour regime ( $D=0.08 \mathrm{~m}$ : runs 12,$23 ; D=0.20 \mathrm{~m}$ : runs 8,28$)$.

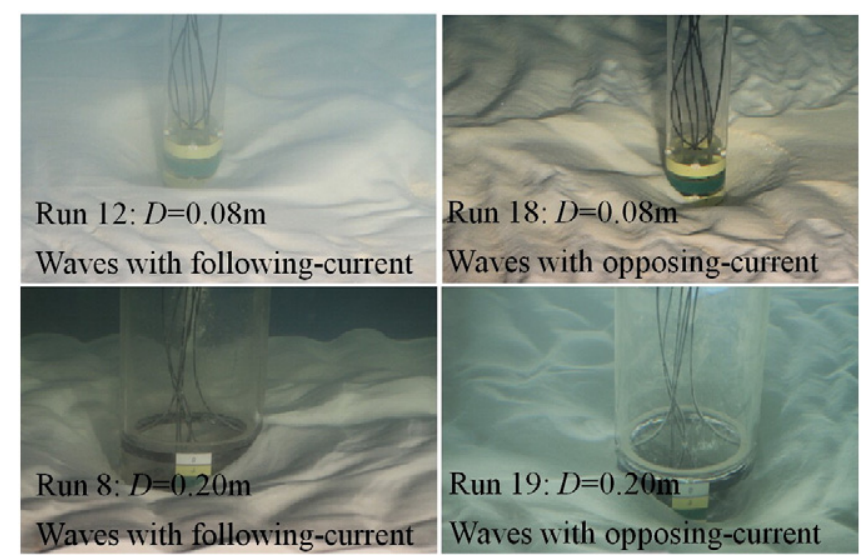

Fig. 11. Scour holes around the pile under the conditions of waves with a followingcurrent and waves with an opposing-current. Live-bed scour regime.

than that for the following-current case, and the equilibrium scour depth for the opposing-current case is also much smaller than that for the following-current case.

The different scour depth developments and equilibrium scour depths between the following-current case and opposing-current case could be explained by the different flow velocities in these cases. As shown in Tables 2 and 3, the maximum flow velocities of runs 12 and 23 (runs 8 and 28) have obvious difference, which should be attributed to the nonlinear interaction between waves and current concerning wave-current angles.

In order to clearly show the detailed difference of the velocities between the following-current case and opposing-current case, a supplementary test was carried out. The velocities at the point $z=$ $0.08 \mathrm{~m}$ representing the flow velocities at the boundary layer were measured under conditions of wave-alone, current-alone, waves with a following-current, and waves with an opposing-current. The flow velocity under current alone is $0.20 \mathrm{~m} / \mathrm{s}$. The wave period is $2.0 \mathrm{~s}$. The wave height under waves alone $\left(H_{0}\right)$ is $9.2 \mathrm{~cm}$. The wave height increased to $9.6 \mathrm{~cm}$ for opposing-current case and decreased to $6.5 \mathrm{~cm}$ for following-current case. The sampling duration of each case was 810 min (approximately 250 wave cycles) with a sampling frequency of $100 \mathrm{~Hz}$ in order to have a statistically time independent average velocity (or phase-averaged velocity).

The measured phase-averaged velocity profiles under waves-alone, waves with a following-current and waves with an opposing-current are shown in Fig. 12. The sums of velocities under waves alone and current alone (following or opposing) are also depicted in Fig. 12 (dashed sinusoidal curves). The actual velocity profiles under waves and current were found obviously different from those suggested by a linear superposition of wave-alone and current-alone velocities. The maximum flow velocity and mean flow velocity for following-current case are much larger than those for opposing-current case, which is consistent with the result of Kemp and Simons (1982, 1983), Klopman (1994) and Olabarrieta et al. (2010). This conclusion indicates that a linear law of velocity superposition does not apply and the wavecurrent angle has much effect on the flow velocity. This wave-current angle effect on the flow velocity should be taken into consideration while predicting the scour depth under a certain wave-current combined condition.

\subsection{Effects of $K C$ and $U_{c w}$ on scour depth}

Sumer and Fredsøe's (2001a) experiments indicated that in the case of combined waves and current, the scour depth is a function of the $K C$ number and the ratio of velocities $\left(U_{c w}\right)$ for live-bed scour regime. The tests results of Rudolph and Bos (2006) generally confirmed the trends presented by Sumer and Fredsøe (2001a). The irregular waves were 


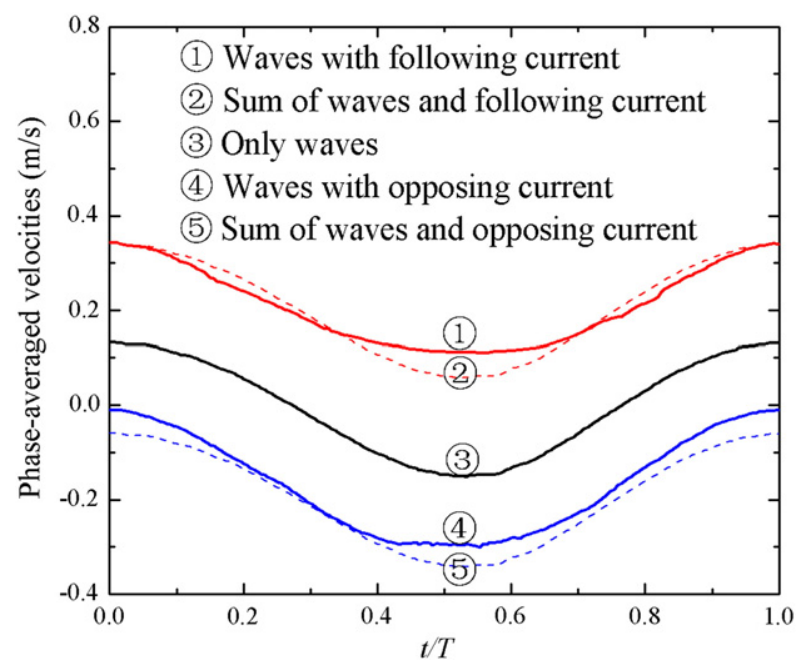

Fig. 12. Comparison of flow velocity variation over one cycle between measured result (phase-averaged) and a sum of the separately measured unidirectional current $\left(U_{c}=0.20 \mathrm{~m} / \mathrm{s}\right)$ and waves $\left(H_{0}=9.2 \mathrm{~cm}, T=2 \mathrm{~s}\right)$ at $z=0.08 \mathrm{~m}$.

used in both experiments and the maximum orbital velocity is calculated from $U_{w m}=\sqrt{2} \sigma_{U}$, in which $\sigma_{U}=$ root-mean-square (RMS) value of the orbital velocity at the bottom, defined by $\sigma_{U}^{2}=$ $\int_{0}^{\infty} S_{U}(f) d f$, in which $S_{U}(f)=$ power spectrum of the orbital velocity corresponding to the wave component of the flow; and $f=$ wave frequency. The $K C$ number is calculated based on $U_{w m}$ and the peak frequency of the wave power spectrum $\left(f_{p}\right)$, i.e. $K C=\frac{U_{w m}}{D f_{p}}=\frac{\sqrt{2} \sigma_{U}}{D f_{p}}$.

The present measured scour depths in live-bed scour regime are plotted in Fig. 13 along with those of Sumer and Fredsøe (2001a) and Rudolph and Bos (2006). It can be seen in Fig. 13(a) that the variation trend of $S / D$ with $U_{c w}$ of the present result is consistent with that of preceding studies, scattering in a reasonable pattern. For small $K C$ numbers (e.g. $0.4 \leq K C \leq 10$ ), the dependence of $S / D$ on $U_{c w}$ is strong. A slight increase of current component could result in a remarkable increase of scour depth.

Moreover, similar variations of scour depth with $K C$ for present data with those in previous studies have been obtained (see Fig. 13(b)). The scour depth increases with increasing $K C$ number for a fixed value of $U_{c w}$. For different ranges of $U_{c w}$, the measured scour depths versus $K C$ collapse to different curves, which converge towards the same asymptotic value as $K C$ increases. The rapid growth stage of the measured scour depth versus $K C$ under the conditions with relatively large values of $U_{c w}$ (e.g. $U_{c w}=0.65 \pm 0.05$ and $U_{c w}=0.75 \pm 0.05$ ) locates in the $K C$ range with smaller values, compared with that under the condition of moderate values of $U_{c w}$ (e.g. $U_{c w}=0.45 \pm 0.05$ ). $U_{c w}$ represents the relative size of the current velocity component in wave-current combined flow velocity. So a larger value of $U_{c w}$ implies more influence of the current. Sumer et al.'s (1997) experiments have shown that the horseshoe vortex emerges for smaller and smaller $K C$ with increasing $U_{c w}$, which is directly related to the increasing adverse pressure gradient and therefore the more favorable flow environment to the formation of the horseshoe vortex in front of the pile. As shown in Fig. 13(b), for very small $K C$ number condition (e.g. $K C \approx 1$ ), the scour depth could still be great when $U_{c w}$ is large enough (e.g. $U_{c w} \geq 0.6$ ) because introducing a comparatively strong current in the waves enormously lowers the critical $K C$ number for the threshold of horseshoe vortex.

It was concluded by Sumer and Fredsøe (2001a) that the scour depth approaches the values obtained in the case of the current alone for $U_{c w} \geq 0.7$ and $K C \geq 4$, implying an independence of scour depth on $K C$ in this condition. The present result in Fig. 13(b) reveals that the scour depth is still influenced quite substantially by $K C$ for $U_{c w} \geq 0.6$ when $K C<4$.

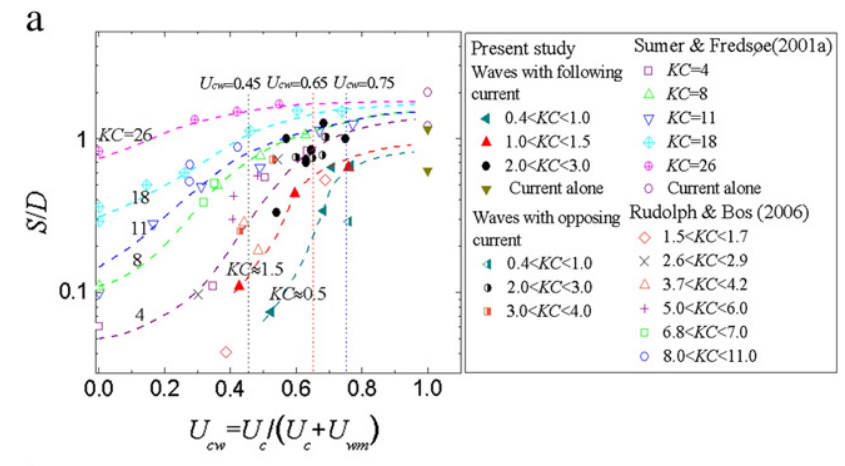

b

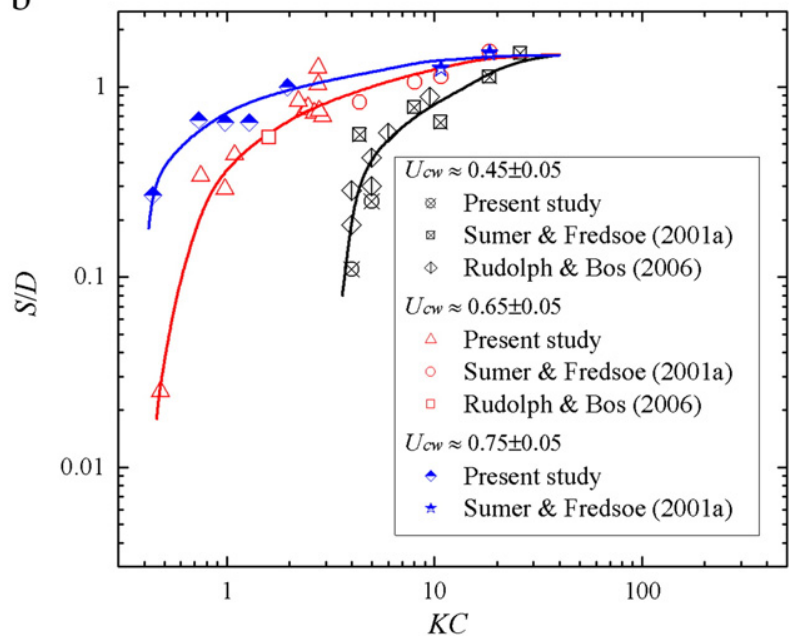

Fig. 13. Equilibrium scour depth normalized with pile diameter $(S / D)$ vs.: (a) the ratio of velocities $\left(U_{c w}\right)$ for different ranges of $K C$; (b) $K C$ for different ranges of $U_{c w}$. Live-bed scour regime.

\section{Concluding remarks}

Monopile foundations are being widely utilized in shallow-water subsea locations for economically constructing offshore structures, especially the booming offshore wind farms. Unlike the conventional slender piles, the monopile diameter may reach approximately 4.0 to $6.0 \mathrm{~m}$, which bring a relatively low $K C$ number condition in waves. The local scour around the monopile under combined waves and current involves a complicated coupling between wave/current, pile and its surrounding seabed. In this study, a series of flume experiments under wave-current combined condition were conducted. The following conclusions are drawn:

(1) The equilibrium scour depth in combined waves and current is greater than the linear sum of those in waves and current separately. This nonlinearity effect is particularly obvious when the sand-bed condition turns from clear-water to live-bed regime due to the superimposition of waves. Moreover, the time development of scour depth at a monopile in combined waves and current is much faster than that in the current or waves alone.

(2) Under the action of combined waves and current, the waveinduced pore-pressure is always accompanying the process of local scouring at the monopile. Wave-induced upward seepage force under the wave troughs may weaken the buoyant unit weight of the surrounding sand, which brings the sand-bed more susceptible to scouring.

(3) The maximum flow velocity for following-current case is much larger than that for opposing-current case. The different velocities between following-current case and opposing-current case have effects on the time development of scour depths and equilibrium scour depths. 
(4) For small values of $K C$ (e.g. $0.4 \leq K C \leq 10$ ) for the component of waves in the combined waves and current, a slight increase of current component $\left(U_{c w}\right)$ could result in a significant increase of equilibrium scour depth. In the current-dominated flow regime, the dependence of scour depth on $K C$ is obvious for $K C<6$. The scour depth could be still significant for very small $K C$ number (e.g. $K C \approx 1$ ) when $U_{c w} \geq 0.6$.

\section{Acknowledgment}

This work is financially supported by the National Natural Science Foundation of China (Grant Nos. 11232012, 10872198) and the Major State Basic Research Development Program of China (973 Program) (Grant No. 2014CB046204). Technical assistance in the flume experiments from Mr. Xi-Ting Han, Mr. Qixian Gong, Senior Engineer Chi Tang and Mr. Fulin Zhang is greatly appreciated.

\section{References}

Breusers, H., Nicollett, G., Shen, H., 1977. Local scour around cylindrical piers. J. Hydraul. Res. 15, 211-252

Debnath, K, Chaudhuri, S., 2010. Bridge pier scour in clay-sand mixed sediments at nearthreshold velocity for sand. J. Hydraul. Eng. 136, 597-609.

Dey, S., Raikar, R., 2007. Characteristics of horseshoe vortex in developing scour-holes at piers. J. Hydraul. Eng. 133 (4), 399-413.

Eadie, R.W., Herbich, J.B., 1986. Scour about a single, cylindrical pile due to combined random waves and current. Proceedings of the 20th Coastal Engineering Conference, pp. $1858-1870$

Grant, W.D., Madsen, O.S., 1979. Combined wave and current interaction with a rough bottom. J. Geophys. Res. 84 (C4), 1797-1808.

Gratiot, N., Mory, M., 2000. Wave-induced sea bed liquefaction with application to mine burial. Proceedings of the 10th International Offshore and Polar Engineering Conference pp. 600-605.

Hoffmans, G.J.C.M., Verheij, HJ. 1997. Scour Manual. A.A. Balkema, Rotterdam, Netherlands

Kemp, P.H., Simons, R.R., 1982. The interaction between waves and a turbulent current: waves propagating with the current. J. Fluid Mech. 116, 227-250.

Kemp, P.H., Simons, R.R., 1983. The interaction between waves and a turbulent current: waves propagating against the current. J. Fluid Mech. 130, 73-89.

Klopman, G., 1994. Vertical structure of the flow due to waves and currents. Progress Report H840.30, Part II. Delft Hydraulics.

Kobayashi, T., Oda, K., 1994. Experimental study on developing process of local scour around a vertical cylinder. Proceedings of the 24th International Conference on Coastal Engineering. , 2(93), pp. 1284-1297.
Li, X.J., Gao, F.P., Yang, B., Zang, J., 2011. Wave-induced pore pressure responses and soil liquefaction around pile foundation. Int. J. Offshore Polar Eng. 21 (3), 233-239.

Melville, B.W., Chiew, Y.M., 1999. Time scale for local scour in bridge piers. J. Hydraul. Eng. 125, 59-65.

Melville, B.W., Coleman, S.E., 2000. Bridge Scour. Water Resources Publications, LLC, CO, USA.

Melville, B.W., Sutherland, A.J., 1988. Design method for local scour at bridge piers. J. Hydraul. Eng. 114 (10), 1210-1226.

Olabarrieta, M., Medina, R., Castanedo, S., 2010. Effects of wave-current interaction on the current profile. Coast. Eng. 57, 643-655.

Petersen, T.U., Sumer, B.M., Fredsøe, J., 2012. Time scale of scour around a pile in combined waves and current. Proceedings of the Sixth International Conference on Scour and Erosion, pp. 981-988.

Raudkivi, A.J., Ettema, R., 1983. Clear-water scour at cylindrical piers. J. Hydraul. Eng. 109 (3), 338-350.

Rudolph, D., Bos, K., 2006. Scour around a monopile under combined wave-current conditions and low KC-numbers. Proceedings of the Sixth International Conference on Scour and Erosion, pp. 582-588.

Sakai, T., Hatanaka, K., Mase, H., 1992. Wave-induced effective stress in seabed and its momentary liquefaction. J. Waterw. Port Coast. Ocean Eng. 118 (2), 202-206.

Sheppard, D.M., Odeh, M., Glasser, T., 2004. Large scale clear-water local pier scour experiments. J. Hydraul. Eng. 130 (10), 957-963.

Sørensen, S.P.H., Ibsen, L.B., Frigaard, P., 2011. Experimental evaluation of backfill in scour holes around offshore monopoles. In: Gourvenec, S., White, D. (Eds.), Frontiers in Offshore Geotechnics II. Taylor \& Francis Group, London, UK, pp. 617-622.

Soulsby, R., 1997. Dynamics of Marine Sands. Thomas Telford, UK.

Sumer, B.M., Fredsøe, J., 2001a. Scour around pile in combined waves and current. J. Hydraul. Eng. 127 (5), 403-411.

Sumer, B.M., Fredsøe, J., 2001b. Wave scour around a large vertical circular cylinder. J. Waterw. Port Coast. Ocean Eng. 127 (3), 125-134.

Sumer, B.M., Fredsøe, J., 2002. The Mechanics of Scour in the Marine Environment. World Scientific, Singapore.

Sumer, B.M., Fredsøe, J., Christiansen, N., 1992. Scour around a vertical pile in waves. J. Waterw. Port Coast. Ocean Eng. 118 (1), 15-31.

Sumer, B.M. Christiansen, N. Fredsøe, J. 1997. Horseshoe vortex and vortex shedding around a vertical wall-mounted cylinder exposed to waves. J. Fluid Mech. $332,41-70$

Sumer, B.M., Hatipoglu, F., Fredsoe, J., 2007. Wave scour around a pile in sand, medium dense and dense silt. J. Waterw. Port Coast. Ocean Eng. 133 (1), 14-27.

Sumer, B.M., Petersen, T.U., Locatelli, L., Fredsøe, J., Musumeci, R.E., Foti, E., 2013. Backfilling of a scour hole around a pile in waves and current. J. Waterw. Port Coast. Ocean Eng. 139 (1), 9-23.

Umeda, S., 2011. Scour regime and scour depth around a pile in waves. J. Coast. Res. 64, 845-849.

Whitehouse, R., 1998. Scour at Marine Structures: a Manual for Practical Applications. Thomas Telford, London.

Zanke, U.C.E., Hsu, T.W., Roland, A., Oscar, L., Reda, D., 2011. Equilibrium scour depths around piles in noncohesive sediments under currents and waves. Coast. Eng. 58, 986-991. 